\title{
Efeitos do método de Reeducação
Postural Global (RPG) no tratamento da cifose de scheuermann
}

Effects of the method of global postural reeducation $(R P G)$ in the treatment FisiSenectus. Unochapecó of kyphosis scheuermann Ano 1 - Edição especial - 2013 p. $10-19$

\section{Tatiana Comerlato}

Mestre, URI-Erechim, taticomerlato@hotmail.com

\section{Suelen Scanegatta}

Fisioterapeuta, URI-Erechim,suellen_scanegatta@yahoo.com.br

\section{Daniele Rosset}

Acadêmica, URI-Erechim, danielerosset@yahoo.com.br

\section{Resumo}

Introdução: A Cifose de Scheuermann é uma patologia que acomete adolescentes em fase de crescimento, provocando o aumento da curvatura normal da região torácica no plano sagital. Objetivos: Este estudo teve o objetivo de avaliar os efeitos do tratamento fisioterapêutico baseado no método RPG em um adolescente, do sexo masculino, com 16 anos de idade e diagnóstico médico de Cifose de Scheuermann, comprovado por exames de imagem. Materiais e métodos: 0 tratamento foi realizado duas vezes por semana, com duração de 50 minutos cada sessão, totalizando 20 sessões. Foram avaliadas pré e pósintervenção, a postura corporal, por meio de imagem fotográfica; a força da musculatura respiratória por meio das medidas de PImáx e PEmáx e expansibilidade torácica por meio de cirtometria. A análise dos resultados foi realizada de forma descritiva. Resultados: Os resultados deste estudo permitiram inferir que com o tratamento proposto não houve diminuição da curva torácica, permanecendo a mesma medida do ângulo de Cobb inicial. Conclusão: Houve melhora na postura, visível nas imagens fotográficas, e melhora na força muscular inspiratória e expiratória e na expansibilidade torácica.

\section{Palavras-chave}

Cifose de Scheuermann. Músculos respiratórios. Reeducação postural global. 


\begin{abstract}
Introduction: The Scheuermann's kyphosis is a condition that affects adolescents during growth, causing an increase in the normal curvature of the thoracic region in the sagittal plane. Objective: This study aimed to evaluate the effects of physical therapy method based RPG in a teenager, male, 16 years of age and those diagnosed with Scheuermann's kyphosis, confirmed by imaging. Materials and Methods: The treatment was performed twice a week, lasting 50 minutes each session, totaling 20 sessions. Were assessed pre and post intervention, body posture, through photographic imaging, the respiratory muscle strength by measuring MIP and MEP and chest expansion through cirtometry. The analysis was performed descriptively. Results: The results of this study conclude that the proposed treatment no decrease of the thoracic curve, remaining the same as the initial Cobb angle. Conclusion: There was an improvement in posture, visible in the photographic image, and improvement in muscle strength and inspiratory and expiratory chest expansion.
\end{abstract}

\title{
Keywords
}

Scheuermann's kyphosis. Respiratory muscles. Global postural reeducation.

\section{Introdução}

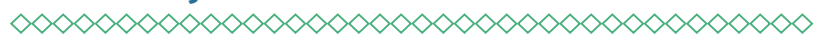

A Cifose de Scheuermann ou cifose juvenil é uma patologia que acomete adolescentes em fase de crescimento, provocando o aumento da curvatura normal da região torácica no plano sagital. Caracteristicamente fixa, é causada por uma deformidade em forma de cunha, de uma ou mais vértebras ${ }^{1-2}$. Os valores fisiológicos da cifose torácica apresentam grandes variações nos indivíduos, sendo considerados normais entre 20 e 40 graus $^{3}$. Além da importante e incomoda deformidade estética, o aumento da cifose torácica pode acarretar restrições na mobilidade do tórax e desequilíbrios musculares que podem afetar a mecânica muscular e provocar inclusive déficit respiratório ${ }^{4,5}$.

São poucas as referências disponíveis na literatura acerca do tratamento conservador da Cifose de Sheuermann. Alguns autores falam sobre o tratamento por meio do uso de colete rígido (MiIwaukee), relatando ser eficaz no tratamento da patologia ${ }^{6}$, porém sabe-se ser um método pouco aceito pelos adolescentes por ser um tanto incomodo e devido à aparência desagradável que possui. Os autores que citam o tratamento por meio de exercícios são pouco precisos quanto à forma de aplicação e resultados destes. Quanto ao tratamento cirúrgico, embora eficaz, é deixado apenas para os casos mais graves, devido aos possíveis riscos do procedimento ${ }^{7}$.

A fisioterapia dispõe de diversas técnicas que podem ser utilizadas no tratamento de alterações posturais, entre elas a Reeducação Postural Global (RPG). Este método propõe buscar o equilíbrio muscular por meio de posturas de correção que trabalham alongamento muscular global, fortalecimento, consciência corporal e respiração, ao mesmo tempo, através do conhecimento das cadeias musculares, procurando harmonizá-las ${ }^{8,9}$. Alguns trabalhos salientam a eficácia deste método no alongamento da musculatura respiratória $^{10-11}$, um grupo muscular possivelmente afetado em indivíduos portadores de Cifose de Scheuermann, devido ao desequilíbrio postural que esta patologia provoca, principalmente na região torácica. No entanto, não foram encontradas referências do uso dessa técnica no tratamento da Cifose de Scheuermann.

Considerando a proposta do método de RPG e buscando evidências científicas sobre os efeitos do método no tratamento da Cifose de Scheuermann, realizou-se o presente trabalho, que consiste em um estudo de caso que teve por objetivo avaliar os efeitos do RPG, sobre a correção postural, força dos músculos respiratórios e expansibilidade torácica, em um indivíduo de 16 anos, com diagnóstico de Cifose de Scheuermann.

\section{Materiais e métodos}

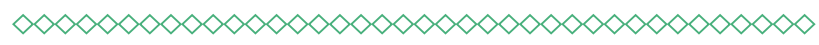

0 presente estudo constituiu um estudo de caso, experimental-descritivo do tipo intervenção, e tem abordagem quantitativa e qualitativa. Foi aprovado pelo Comitê de Ética em Pesquisa da 
Universidade Regional Integrada do Alto Uruguai e das Missões - campus de Erechim, por meio do Protocolo n 007/TCH.

A escolha da mostra foi feita de forma intencional, correspondendo a um indivíduo do sexo masculino, com 16 anos de idade e diagnóstico médico de Cifose de Scheuermann, que, por orientação médica, procurou tratamento fisioterapêutico. Após a identificação do voluntário, foi solicitada a autorização do responsável pelo adolescente participante do estudo, por se tratar de menor de idade, por meio da assinatura do Termo de Consentimento Livre e Esclarecido, conforme resolução 196/1996 do Conselho Nacional de Saúde, o qual trata das Diretrizes regulamentadoras de Pesquisa Envolvendo Seres Humanos.

A avaliação constou de anamnese, avaliação postural e registro fotográfico da postura (no plano sagital, na posição de perfil direito, esquerdo e com flexão do tronco à frente; e no plano frontal, nas posições de frente e de costas); avaliação da força muscular respiratória e avaliação da expansibilidade torácica.

Para aquisição das fotos a câmera fotográfica foi posicionada a três metros do paciente, sobre uma mesa, e nivelada por meio de um nível d'água, a fim de garantir a horizontalidade desta. Foi utilizado o flash com o objetivo de reproduzir a mesma luminosidade na avaliação pré e pós-tratamento. 0 paciente foi posicionado sobre um quadrado de papelão, cujo tamanho se ajustou exatamente à distância existente entre os pés do posturógrafo, e onde estavam desenhadas linhas para o posicionamento do paciente, de forma central em relação ao posturógrafo.

Para mensuração das pressões inspiratórias e expiratórias máximas foi utilizado um Manovacuômetro digital modelo MVD 30 - Globalmed, com sistema de autocalibragem, com intervalo operacional de $300 \mathrm{cmH2O}$. As medidas foram coletadas pelo pesquisador sob comando verbal, sendo realizadas com o voluntário sentado e tendo as narinas ocluídas por uma pinça nasal para evitar o escape de ar. A PIMáx foi medida durante esforço iniciado a partir do volume residual (VR), enquanto que a PEMáx foi medida a partir da capacidade pulmonar total (CPT). O voluntário executou cinco esforços de inspiração e expiração máximas, tecnicamente satisfatórias, isto é, sem vazamento perioral de ar e com valores próximos entre si, sendo considerada para o estudo a medida de maior valor ${ }^{12}$.

Para avaliação da mobilidade toracoabdominal foi utilizada uma fita métrica convencional e realizada a medida das circunferências torácicas (axiliar e xifoideana), durante as fases expiratórias e inspiratórias máximas. A diferença entre essas medidas forneceu informações do grau de expansibilidade torácica ${ }^{10}$.

A intervenção Fisioterapêutica foi constituída por um programa de alongamento, fortalecimento e conscientização postural, baseado em posturas do método RPG, realizado com a regularidade de duas vezes por semana, durante 10 semanas, totalizando 20 sessões. De acordo com a tolerância do paciente e a progressão do tratamento as posturas foram evoluindo em grau de dificuldade. Nas primeiras sessões foi priorizado o aprendizado da respiração e controle das compensações posturais. Antes da realização da postura "rã no chão com os braços abertos" foram realizadas pompagens dos músculos trapézio, esternocleidomastoideo, escalenos e elevadores da escápula.

Para realização da postura "rã no chão com os braços abertos", o paciente foi posicionado em decúbito dorsal sobre a maca de RPG, com os ombros a aproximadamente 45 graus de abdução, antebraços em supinação, palmas das mãos voltadas para cima; membros inferiores com abdução, flexão de quadril e joelhos fletidos até a completa aposição das plantas dos pés. Durante a realização da postura, os membros superiores seguiram em abdução de ombros, com alongamento progressivo dos músculos peitorais, evitando compensações. Da mesma forma, os membros inferiores, em aposição, avançaram em sentido caudal, visando principalmente o alongamento do músculo psoas ilíaco, mantendo a curvatura lombar em contato com a superfície de apoio ${ }^{13}$.

O terapeuta utilizou comandos verbais e contatos manuais, solicitando a manutenção do alinhamento e as correções posturais necessárias. 0 paciente foi solicitado, durante o tempo de manutenção da postura, a realizar inspirações tranquilas seguidas de expirações prolongadas, visando o alongamento da cadeia muscular respiratória. Com o decorrer do tratamento e evolução do pa- 
ciente foram incluídas as posturas "sentada" e "em pé no centro".

Na postura sentada o paciente foi posicionado sentado sobre a maca do RPG, braços ao longo do corpo em posição anatômica; membros inferiores com abdução, flexão de quadril e joelhos fletidos até a completa aposição das plantas dos pés. 0 terapeuta tracionava o occipital para cima e solicitava um movimento de recuo do queixo, alinhando no mesmo plano vertical o occipital, a região dorsal média e o sacro. 0 paciente alongava progressivamente os membros inferiores, alinhando os joelhos, puxando as pontas dos pés para $\mathrm{si}^{13}$.

Nas posturas em pé a correção das costas como um todo se fez como descrito na postura sentada. Os pés ficaram apoiados no solo, com calcanhares juntos e a parte anterior do pé levemente afastada. Os quadris levemente fletidos em rotação externa e joelhos semiflexionados. 0 paciente estendeu o joelho pouco a pouco, em uma rotação correta procurando não lordosar a região lombar previamente corrigida ${ }^{13}$.

Foram utilizadas duas posturas em cada sessão, sendo que o terapeuta realizou a progressão da postura até o limite possível para o voluntário, favorecendo o alongamento progressivo das cadeias musculares envolvidas na postura durante o tratamento. Cada postura foi mantida em média por $20 \mathrm{~min}$.

\section{Resultados e discussão}

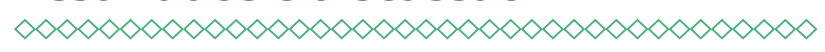

A comparação dos resultados, pré e pós-tratamento, foi realizada por meio de análise descritiva simples.

O resultado da avaliação postural realizada por meio de imagens fotográficas pode ser observado nas figuras de 1 a 5 . No plano frontal e posições "de frente" (figura 1), pode-se observar melhor alinhamento dos mamilos e maior equilíbrio em relação ao ângulo de Talles, e na posição "de costas" (figura 2), observa-se menor enrolamento anterior do ombro direito, ângulo inferior das escápulas menos saliente, devido a menor anteriorização de ambos os ombros, e maior simetria em relação à linha média. Observa-se também diminuição na rotação do tronco para direita, pela maior simetria de cabeça, ombros e membros inferiores em relação à linha média.

Segundo Kendall et al. ${ }^{4}$, na vista posterior, o fio de prumo deve coincidir com a linha média da cabeça e com os processos espinhosos cervicais. Neste alinhamento esquelético ideal as articulações se encontram em uma posição estável e o peso corporal está equilibradamente distribuído, as curvas da coluna estão normais e a pelve está na posição neutra. A cabeça fica ereta em uma posição bem equilibrada que minimiza a sobrecarga sobre a musculatura cervical. Para Dufour et al. ${ }^{14}$, de costas, deve haver uma simetria entre os lados direito e esquerdo do indivíduo, passando o fio de prumo no meio do occipício e no meio dos calcanhares. Entre estas duas extremidades, todos os processos espinhosos e prega glútea devem estar alinhados atrás do fio. Deve haver simetria entre o bordo inferior das escápulas e as EIPS em relação a linha vertical.

No plano sagital (figura 3), observa-se diminuição da anteriorização da cabeça, diminuição na retificação de cervical, diminuição do enrolamento anterior dos ombros e maior equilíbrio das curvas da coluna no plano sagital. No alinhamento considerado ideal, na vista lateral, a linha de prumo deve coincidir com uma posição ligeiramente anterior ao maléolo lateral e ao eixo da articulação do joelho e ligeiramente posterior ao eixo do quadril; deverá passar pelo corpo das vértebras lombares, pela articulação do ombro, corpo da maioria das vértebras cervicais, meato auditivo externo e levemente posterior ao ápice da sutura coronal. A posição ideal para cabeça é aquela na qual ela encontra-se bem equilibrada, não deve estar inclinada nem rodada. 0 fio de prumo deve passar pelo lóbulo da orelha ${ }^{4}$.

$\mathrm{Na}$ postura de inclinação do tronco à frente (figura 4), observa-se diminuição do ângulo lombo-pélvico, diminuição do encurtamento dos músculos lombares e consequente diminuição da retificação da curva lombar; diminuição no encurtamento de músculos posteriores da cervical e maior equilíbrio entre curva lombar e torácica, provocado pela harmonização e melhora na flexibilidade da cadeia muscular posterior.

Toda hipercifose tem suas compensações para, dessa forma, poder manter a sustentação do cor$\mathrm{po}^{5}$. Juntamente com o aumento da curvatura cifó- 
tica torácica está associada, na maioria das vezes, a projeção da cabeça para frente da linha de gravidade, ocasionando a hiperextensão da coluna cervical e alterações da cintura escapular, tais como a abdução das escápulas e a anteriorização dos ombros. A musculatura peitoral se torna hipertônica e a dorsal, hipotônica. ${ }^{4,5}$.

Os resultados visíveis nas imagens fotográficas permitem inferir que o tratamento realizado foi benéfico, pois a postura do voluntário desta pesquisa aproximou-se da postura considerada ideal, após o tratamento desenvolvido. 0 método de RPG apresenta vantagens em relação a outros tipos de alongamento por manter a musculatura alongada por tempo prolongado e alongar os músculos em cadeias, impedindo compensações em músculos próximos ou distantes, possibilitando a melhora da flexibilidade e da força ${ }^{10}$.

Os resultados referentes à cirtometria são apresentados na tabela 1. Observa-se que, após 0 tratamento, houve aumento nas medidas de cirtometria axilar e xifoidiana. Estes resultados podem estar relacionados com o maior equilíbrio postural conseguido após o tratamento e melhora no comprimento e força dos músculos respiratórios, favorecendo maior expansibilidade torácica. A expansibilidade torácica é definida como o movimento observado no tórax durante uma incursão inspiratória e expiratória, e depende da capacidade dos músculos respiratórios em gerar pressão negativa intrapleural eficiente e da integridade da caixa torácica ${ }^{15}$. A ventilação pulmonar está diretamente relacionada com as curvaturas da coluna vertebral e má-formação do tórax ${ }^{16}$.

As medidas de pressão inspiratória e expiratória máximas são apresentadas na tabela 2. Observa-se um incremento de $55 \mathrm{cmH}_{2} \mathrm{O}$ na PiMáx entre os valores pré-intervenção e pós-intervenção, e o aumento da força muscular inspiratória pode estar diretamente associado ao aumento da expansibilidade torácica. A ação mecânica aumentada dos músculos inspiratórios proporciona maior mobilidade toracoabdominal e, consequentemente, uma reorganização de todos os músculos envolvidos na respiração ${ }^{17}$.

A medida inicial da PiMáx do adolescente voluntário da presente pesquisa foi $-84 \mathrm{cmH}_{2} \mathrm{O}$, o que caracteriza uma fraqueza muscular, pois aceita-se como PiMáx normal, para um adulto jovem masculino, por volta de $-125 \mathrm{cmH} 20^{18}$. Já na medida final, o valor subiu para $-135 \mathrm{cmH}_{2} \mathrm{O}$. Isto demonstra a melhora na força dos músculos responsáveis pela inspiração, após o tratamento.

Para medida da PeMax considera-se normal, em média, um valor igual a $100 \mathrm{cmH}_{2} \mathrm{O}^{18}$. Para 0 adolescente da presente pesquisa, o valor inicial apresentava-se em $65 \mathrm{cmH}_{2} \mathrm{O}$, caracterizando uma falência muscular ${ }^{18}$. No pós-intervenção este valor subiu para $85 \mathrm{cmH}_{2} \mathrm{O}$.

As pequenas medidas de PiMáx e PeMáx pré-intervenção podem estar relacionadas com as restrições provocadas pelo encurtamento muscular adaptativo secundário a deformidade cifótica da patologia de Sheuermann. Segundo Verderi ${ }^{5}$, o aumento da curvatura cifótica torácica está associada, na maioria das vezes, a projeção da cabeça para frente da linha de gravidade e alterações da cintura escapular, tais como a abdução das escápulas e a anteriorização dos ombros. Estes desequilíbrios musculares e a manutenção desta postura inadequada podem provocar o encurtamento excessivo da musculatura inspiratória e afetar a mecânica dos músculos respiratórios ${ }^{13}$. Além disso, a hipercifose dorsal pode ocasionar déficit respiratório, devido à redução da capacidade de sustentação da coluna vertebral e diminuição da expansibilidade torácica ${ }^{4,5}$.

A força muscular respiratória é dependente do comprimento do músculo respiratório ${ }^{19}$. Quando um músculo perde sua flexibilidade normal, ocorre uma alteração na relação comprimento-tensão, incapacitando-o de produzir um pico de tensão adequado, o que desenvolve fraqueza com retração muscular ${ }^{11}$. Assim, pode-se inferir que o alongamento promovido pelo trabalho realizado nas posturas de RPG promoveu melhora na força dos músculos respiratórios, sendo que o incremento de força foi maior para os músculos inspiratórios (escalenos, peitoral menor, intercostais externos e diafragma), fato que pode estar associado as expirações prolongadas realizadas durante as posturas, que foram realizadas com o objetivo de alongar a cadeia muscular inspiratória.

Autores referem que, após uma única sessão de intervenção pelo método de RPG em 20 mulheres jovens saudáveis, a PImáx e a cirtometria torácica na região axilar apresentaram aumento es- 
tatisticamente significantes que foram atribuídos ao aumento da força muscular respiratória e da mobilidade torácica como efeito do alongamento, que envolveu a cadeia muscular respiratória em postura global ${ }^{10}$.

Conforme Souchard ${ }^{20}$, as posturas "rã no chão" e "rã no ar" permitem melhor estabilidade dos pontos de inserção do diafragma, sendo ideal para que se trabalhe o alongamento dos músculos diafragma, esternocleidomastoideo, escalenos, intercostais, músculos próprios do dorso, peitoral maior e menor. 0 ganho da flexibilidade do diafragma é possível pela fixação de suas inserções cervicais, lombares e costais, associada à contração excêntrica do diafragma.

\section{Conclusão}

$\infty \times \infty \times \infty \times \infty \times \infty \times \infty \times \infty \times \infty \times \infty \times \infty \times \infty \times \infty \times \infty)$

A melhora na postura, expansibilidade torácica e pressões inspiratórias e expiratórias máximas, na presente pesquisa, demonstrou que as posturas do método RPG foram benéficas no tratamento deste paciente de 16 anos, com Cifose de Sheuermann. A partir dos resultados deste estudo, pode-se inferir ser o método RPG uma boa opção no tratamento conservador de pacientes com essa patologia, quando a cirurgia não estiver indicada.

$\mathrm{Na}$ literatura pesquisada não foram encontrados estudos referentes à Cifose de Scheuermann tratada por meio do método RPG. Outros estudos então devem ser realizados, priorizando adolescentes no início da fase de crescimento, para comprovar os efeitos do método sobre as alterações provocadas por esta patologia.

Sugere-se que próximos estudos tenham maior rigor metodológico na aquisição das fotografias, e acompanhamento por exames de imagem pré e pós-intervenção, o que representou uma limitação do presente trabalho.

\section{Referências}

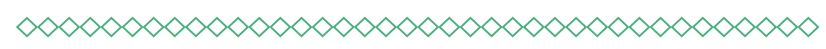

1. Knoplich J. Enfermidades da coluna vertebral: uma visão clínica e fisioterápica. 3a ed. São Paulo: Robe; 2003.
2. Avanzi O, Chih LY, Meves R, Caffaro MFS, Pellegrini JH. Cifose torácica e músculos isquiotibiais: correlação estético-funcional. Acta Ortop Bras. 2007;15(2):93-6

3. Herrero CFPS, Porto MA, Barbosa MHN, Defino HLA. Osteotomia segmentar múltipla para a correção da cifose. Rev Bras Ortop. 2009;44(6):513-17.

4. Kendall FP, Mc Creary EK, Provance, PG. Músculos, provas e Funções. 4a ed. São Paulo: Manole; 1995.

5. Verderi E. Programa de Educação Postural. São Paulo: Phorte; 2001.

6. Elias N, Enokibara RT, Almeida AL, Oliveira LP. Cifose de Scheuermann: Resultados Tardios Após Uso Do Colete De Milwaukee. Rev. Bras. Ortop. 1993;28(4):224-6.

7. Macedo RD'A, Fim M, Fontes BPC. Parafusos pediculares no tratamento da cifose de Scheuermann: resultados e complicações. Rev Bras Ortop. 2008;43(1-2):23-30.

8. Marques AP. Hérnia de disco cervical tratada com Reeducação Postural Global (RPG). Rev. Fisioter. Univ. São Paulo. 1994;1(1):34-7.

9. Toledo PCV, Mello DB, Araújo ME, Daoud EHMD. Efeitos de Reeducação Postural Global em escolares com escoliose. Fisioter. Pesqui. 2011;18(4):329-34.

10. Teodori RM, Moreno MA, Fiore Junior JF, Oliveira ACS. Alongamento da musculatura inspiratória por intermédio da Reeducação Postural Global. Rev. Bras. Fisioter. 2003;7(1):25-30.

11. Moreno MA, Catai AM, Teodori RM, Borges BLA, Castro Cesar M, Silva E. Efeito de um programa de alongamento muscular pelo método de Reeducação Postural Global sobre a força muscular respiratória e a mobilidade toracoabdominal de homens jovens sedentários. J Bras Pneumol. 2007;33(6):679-86.

12. Souza, RB. Pressões respiratórias estáticas máximas. J. Pneumologia. 2002;28(3):155-65.

13. Souchard, PE. Reeducação Postural Global (método do campo fechado). 4a ed. São Paulo: Ícone; 2002. 
14. Dufour M, Péninou G, Neiger H, Génot C, Leroy A, Pierron G, Dupré JM. Cinesioterapia: Avaliações passivas e ativas. São Paulo: Panamericana; 1989. v.1-4.

15. Azeredo, Cac; Queiroz, AN; Fisioterapia Respiratória Moderna. 4a ed. São Paulo: Manole; 2002.

16. Yokohama TV. A prática do Iso-stretching na melhora da expansibilidade toracopulmonar, verificada através da Espirometria e da Cirtometria [Monografias do curso de Fisioterapia]. Cascavel (PR): Unioeste; 2004.
17. Sampaio LMM, Jamami M, Pires VA, Silva A, Costa D. Força muscular respiratória em pacientes asmáticos submetidos ao treinamento muscular respiratório e treinamento físico. Rev. Fisioter. Univ. São Paulo. 2002;9(2):43-8.

18. Godoy ID. Avaliação funcional pulmonar. J. Pneumologia. [online]. 2000;26(5):278-278.

19. Gambaroto G. Fisioterapia Respiratória em Unidade de Terapia Intensiva. São Paulo: Atheneu; 2006.

20. Souchard PE. O diafragma. 3a ed. São Paulo: Summus; 1989.

\section{Anexos}

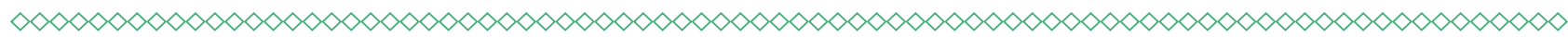

Figura 1 - Imagem fotográfica da posição "de frente" pré-intervenção (A) e pós-intervenção (B)

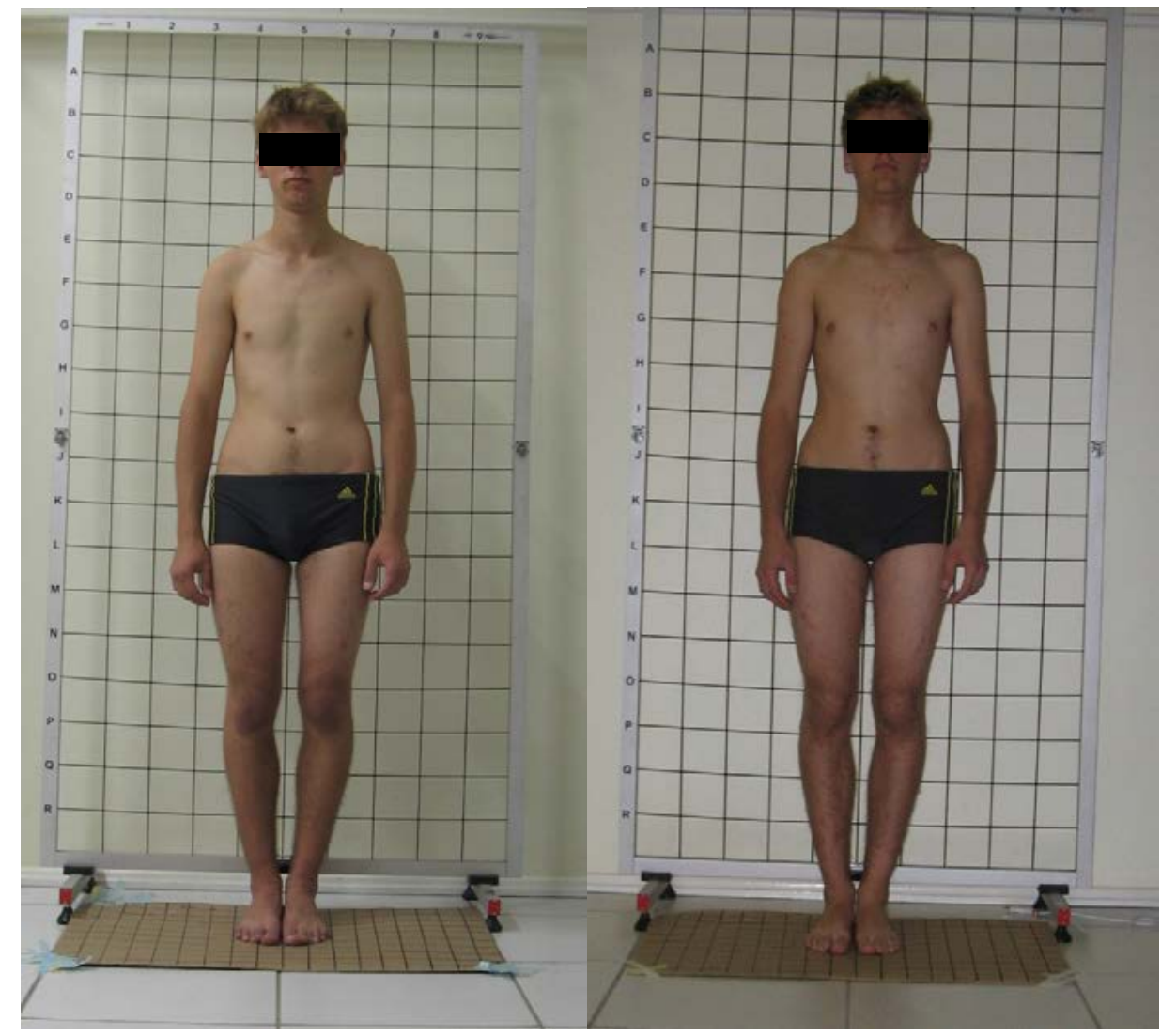

A

B

(clique para voltar ao texto) 
Figura 2 - Imagem fotográfica da posição "de costas" pré-intervenção (A) e pós- intervenção (B)

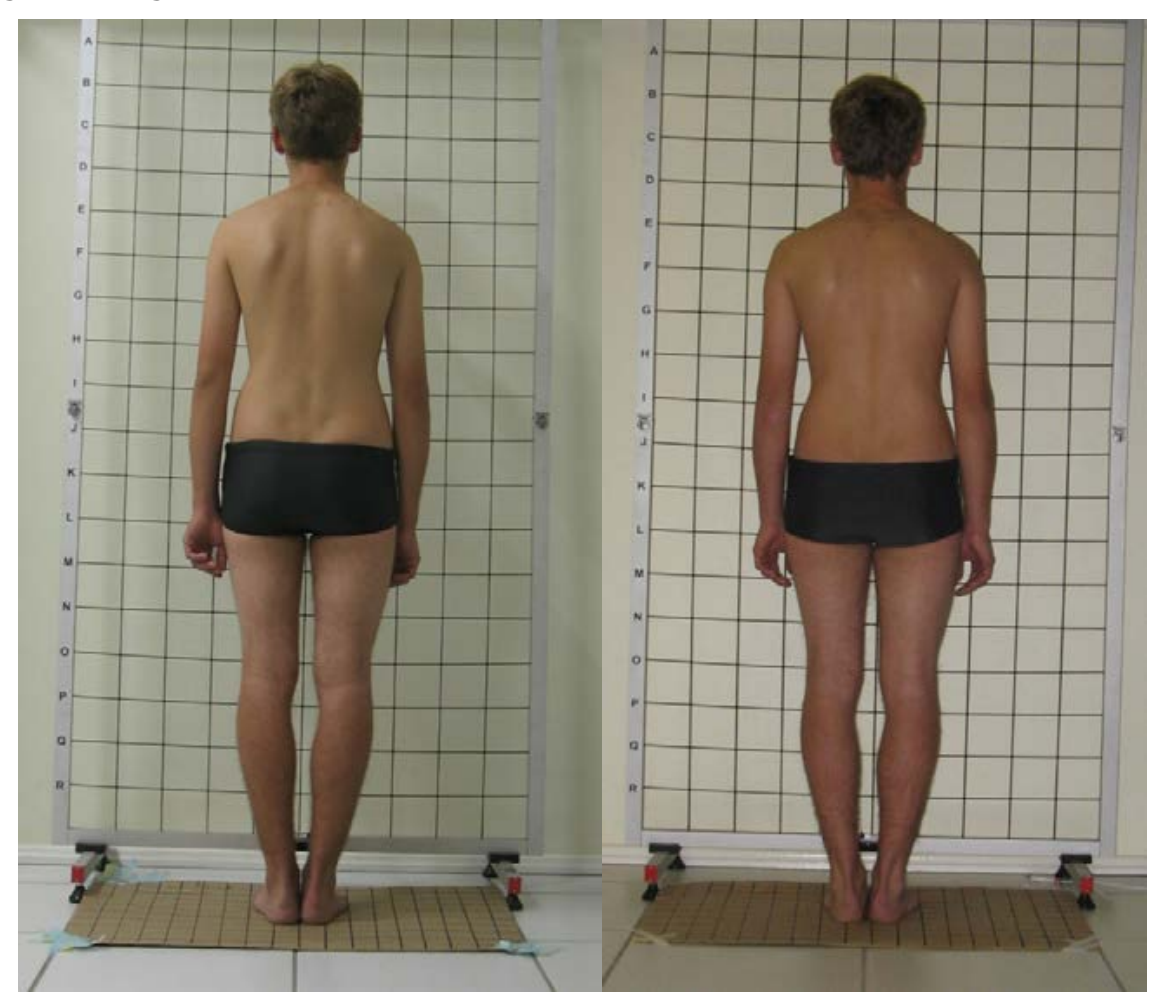

A

B

(clique para voltar ao texto)

Figura 3 - Imagem fotográfica do perfil direito pré-intervenção (A) e pós-intervenção (B) e perfil esquerdo pré-intervenção (C) e pós-intervenção (D)

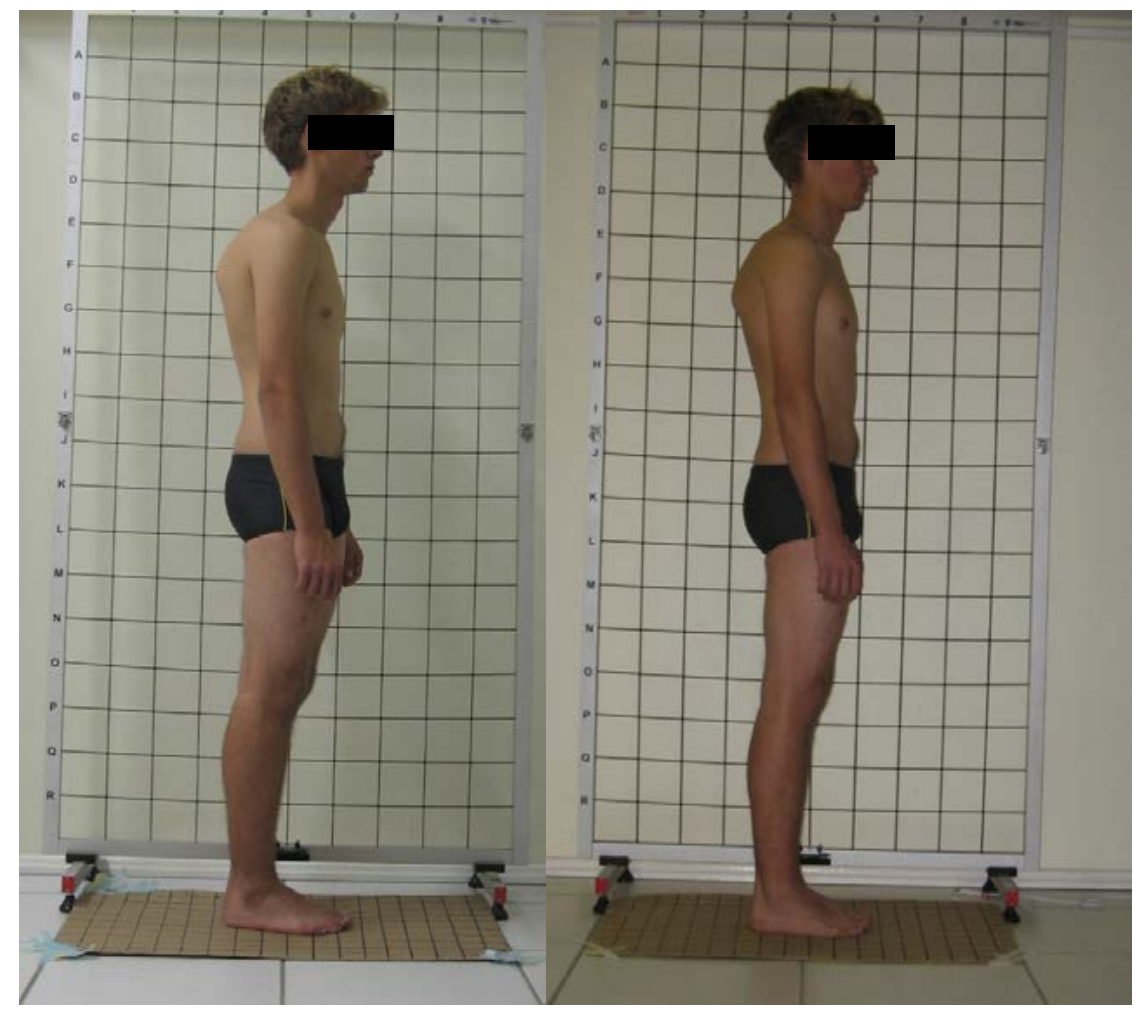

A 


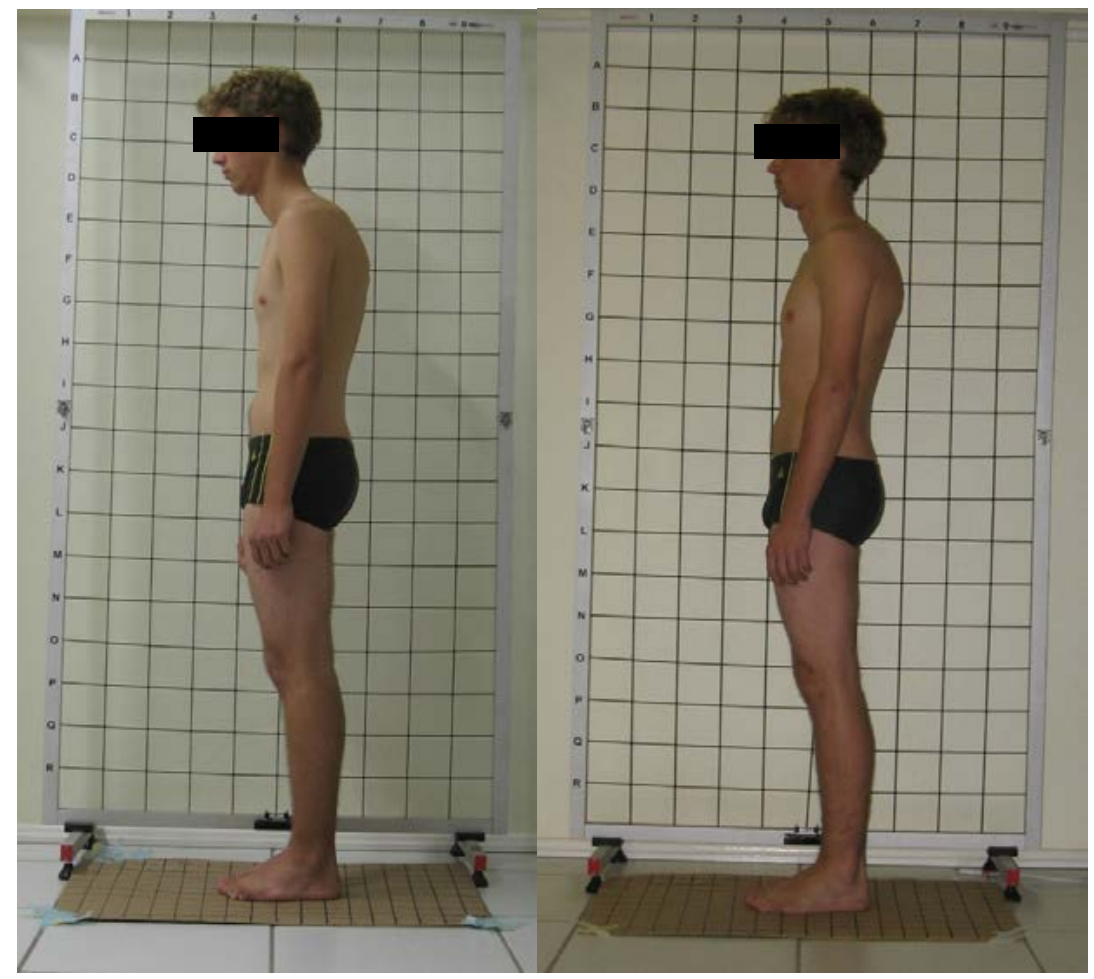

C

D

(clique para voltar ao texto)

Figura 4 - Imagem fotográfica da posição "Inclinação do tronco à frente" pré-intervenção (A) e pós-intervenção (B)

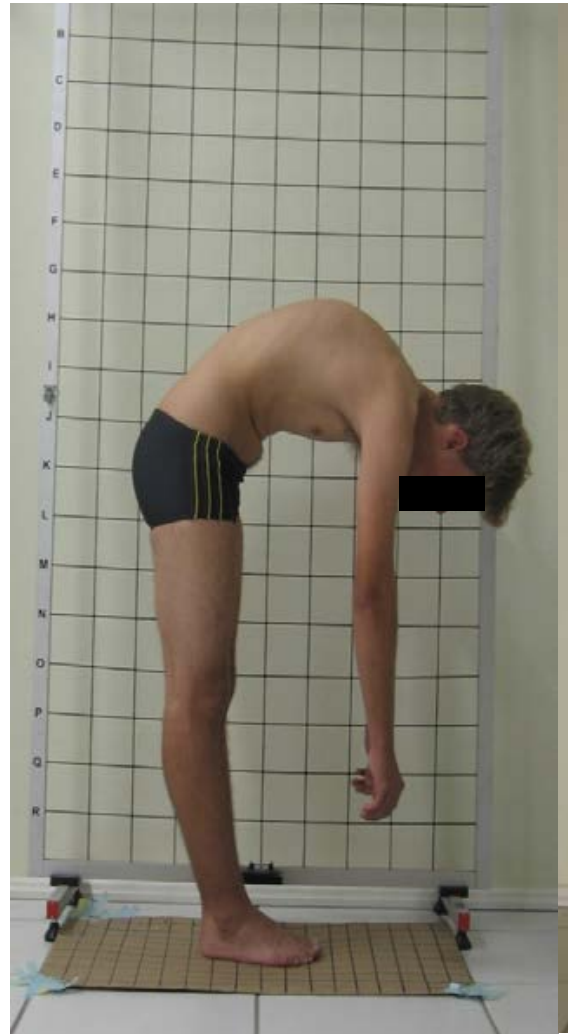

A

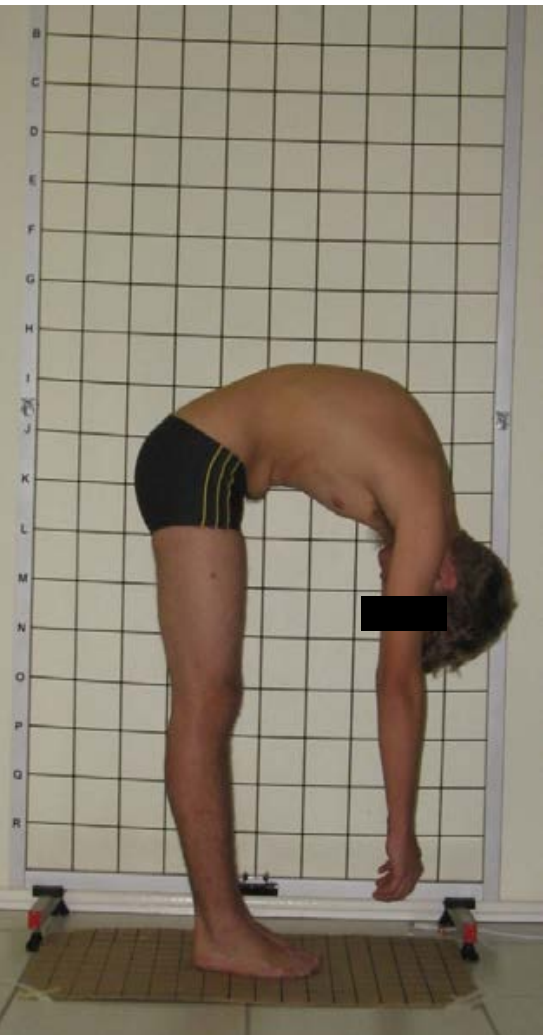

B

(clique para voltar ao texto) 
Tabela 1 - Cirtometria axilar e xifoidiana pré e pós-Intervenção

\begin{tabular}{ccccc} 
& \multicolumn{2}{c}{ Medida na Inspiração $(\mathrm{cm})$} & \multicolumn{2}{c}{ Medida na Expiração $(\mathrm{cm})$} \\
\cline { 2 - 5 } & Pré & Pós & Pré & Pós \\
Cirtometria Axilar & 88 & 96 & 94 & 91 \\
Cirtometria Xifoideana & 95 & 96 & 89 & 88 \\
\hline
\end{tabular}

Fonte: elaboração dos autores.

(clique para voltar ao texto)

Tabela 2 - Pressões inspiratória e expiratória máximas, pré e pós-intervenção

\begin{tabular}{cc} 
Pré-intervenção & Pós-intervenção \\
Pimáx - $84 \mathrm{cmH} 20$ & $-139 \mathrm{cmH} 20$ \\
Pemáx $66 \mathrm{cmH} 20$ & $85 \mathrm{cmH} 2 \mathrm{O}$ \\
\hline
\end{tabular}

Fonte: elaboração dos autores. 